\title{
Abel Matthieu, Devis de la langue française (1559), suivi du Second Devis et principal propos de la langue française (1560)
}

\section{Michele Mastroianni}

\section{(2) OpenEdition}

Journals

\section{Edizione digitale}

URL: http://journals.openedition.org/studifrancesi/7874

DOI: $10.4000 /$ studifrancesi.7874

ISSN: 2421-5856

\section{Editore}

Rosenberg \& Sellier

\section{Edizione cartacea}

Data di pubblicazione: 1 juillet 2009

Paginazione: 381

ISSN: 0039-2944

\section{Notizia bibliografica digitale}

Michele Mastroianni, «Abel Matthieu, Devis de la langue française (1559), suivi du Second Devis et principal propos de la langue française (1560)», Studi Francesi [Online], 158 (LIII | II) | 2009, online dal 30 novembre 2015, consultato il 12 janvier 2021. URL: http://journals.openedition.org/studifrancesi/7874 ; DOI: https://doi.org/10.4000/studifrancesi.7874

Questo documento è stato generato automaticamente il 12 janvier 2021.

\section{cc) $($ ) $\ominus$}

Studi Francesi è distribuita con Licenza Creative Commons Attribuzione - Non commerciale - Non opere derivate 4.0 Internazionale. 


\title{
Abel Matthieu, Devis de la langue française (1559), suivi du Second Devis et principal propos de la langue française (1560)
}

\author{
Michele Mastroianni
}

\section{NOTIZIA}

ABEL MATTHIEU, Devis de la langue française (1559), suivi du Second Devis et principal propos de la langue française (1560), texte original transcrit, présenté et annoté par Alberte JACQUETIN-GAUDET, Paris, Champion, 2008 («Textes de la Renaissance», 137), pp. 279.

1 Dieci anni dopo la comparsa della Deffence, Abel Matthieu riprende le tematiche dell'opera di Du Bellay, scegliendo in parte come modello le Prose della volgar lingua di Bembo, e nello stesso tempo alla «difesa» del volgare aggiunge una rapida descrizione fonetica e morfologica della lingua francese, in una prospettiva conservatrice e nazionalista, come attesta l'uso, nella stampa, della lettre Francoyse, risorgenza modernizzata degli antichi caratteri gotici, sempre più trascurati a vantaggio dei caratteri romani e italici. Giurista di formazione, Matthieu mescola difesa della lingua volgare e critica delle istituzioni giudiziarie che ne hanno fatto uso, offrendo un'interessante testimonianza di come il problema della lingua travalicasse il campo letterario. A. Jacquetin-Gaudet, nell'editare il testo, lo annota con minuziosa puntualità e, nell'introduzione, con altrettanta minuzia raccoglie i dati reperibili su Matthieu, di cui peraltro si sa ben poco, e analizza la struttura dei suoi Devis. 